\title{
Pregnant Women's Satisfaction with the Quality of Antenatal Care At Maternal and Child Health Centers in El-Beheira Governorate
}

\author{
Nemat Ismail Abdel Aziz Ismail, Rasha Mohamed Essa \\ Obstetric and Gynecologic Nursing, Faculty of Nursing, Damnhour University, Damnhour, Egypt
}

\begin{abstract}
:
Background: Quality of antenatal care is seen as a factor closely related to effectiveness, utilization, compliance and continuity of care. Women's satisfaction has been linked to the quality of services given and the extent to which specific needs are met. The aim of this study was to assess pregnant women's satisfaction with the quality of antenatal care at maternal and child health $(\mathrm{MCH})$ centers in El-Beheira Governorate. A descriptive exploratory research design was utilized. The study was conducted at seven MCH centers affiliated to Ministry of Health in El-Beheira Governorate. These centers were chosen through a multi-stage probability sampling technique. A convenience sample of 350 pregnant women who were attending the antenatal clinic. Three tools were used for data collection Tool I: Basic data structured interview schedule. Tool II: Women's satisfaction structured interview schedule. Tool III: Quality of antenatal care observational checklist. Study results revealed more than one half of the study subjects (58.9\%) were unsatisfied with the overall antenatal care services, more than one quarter of them (26.9\%) were moderately satisfied and only $14.2 \%$ were highly satisfied. In addition, more than one-half (57.1\%) of MCH centers had low quality of care. And $28.6 \%$ of them had moderate quality of care, while only $14.3 \%$ of them had high quality. The study concluded that quality of antenatal care provided at studied MCH centers in El-Beheira governorate was poor, this due to lack of proper infrastructure for providing antenatal care, shortage of staff, lack of necessary medications, vaccination, equipments and supplies. The pregnant women were unsatisfied with the antenatal care provided in these centers. It indicates that a decrease in the quality of care level is followed by a decrease in the clients' satisfaction level. Continuous training of the health care providers at maternal and child health centers is recommended as it may improve their performance and consequently raise the quality level.
\end{abstract}

Keywords: women's satisfaction, quality of antenatal care.

\section{Introduction}

Pregnancy is one of the most important events that constitute powerful experience in women's lives and indeed in the lives of their families. Although pregnancy is a normal physiological process, it is associated with certain risks to health and survival both for the woman and for the infant she bears. ${ }^{(1)}$ These risks are present in every society and in every setting. In developed countries they have been largely overcome because every pregnant woman has to take special care during pregnancy and childbirth. In developing countries where each pregnancy represents a journey into the unknown from which all too many woman never return, due to lack of care provision. ${ }^{(2)}$

According to the World Health Organization (WHO), the worldwide estimated maternal mortality ratio (MMR) in year 2010 was 210 deaths/100.000 live births among women aged 15-49 years, showing a decline of 43\% from the level in 2015. In Egypt, maternal mortality ratio has declined dramatically from 174/100000 live births in 1992-1993 to 67.6 / 100000 live births in 2005 to 44.6 / 100000 live births in 2009 to 33/100.000 live births in 2015. (3) Such decrease in MMR reflects the country's effort in achievement of the millennium developmental goals. The target of those goals was to reduce MMR by three quarters by 2030 . One of the corner stones for achievement of these goals is the provision of quality antenatal care. ${ }^{(4)}$

Antenatal care (ANC) refers to the comprehensive health supervision that is given to a pregnant woman from the time that conception is confirmed until the beginning of labor. ${ }^{(5,6)}$ It is important in preventing, monitoring, early detecting, and treating health problems for pregnant women and her family. ${ }^{(7)}$

ANC is mostly provided by nurse, nurse midwives, and obstetricians. Professionals from other discipline, such as nutritionists, health visitor, social workers, counselors, health advocates, may also be involved in this care. It is provided through a number of planned antenatal visits (totaling 14 visits) scheduled as follows: the initial visit takes place as soon as the woman thinks she might be pregnant. ${ }^{(7)}$ The major objectives of this visit are to introduce the woman to the maternity service, confirm or rule out a diagnosis of pregnancy, ascertain risk factors, determine the due date, and provide education about maintaining a healthy 
pregnancy. However, the first visit is usually the longest because it establishes baseline data relevant to planning health-promotion strategies for initial and every subsequent visit. ${ }^{(5,8)}$

Assessment during the first antenatal visit includes history taking, physical examination and laboratory investigation as well as health teaching and development of delivery plan which will be reviewed at subsequent visits. Subsequent visits take place monthly until 28 gestational weeks. Then fortnightly until 36 weeks and weekly thereafter until delivery. During this visits the following activities are completed: measurement of weight and blood pressure, urine testing for protein, glucose and ketones, fundal height measurement to assess fetal growth assessment of fetal heart rate, tetanus toxoid immunization. ${ }^{(9,10)}$

Out of this schedule the pregnant woman should promptly visit the ANC clinic if any of the warning signs develops. Specifically: severe frontal headache, blurring of vision or double vision, persistent vomiting, swelling of face and hands, fever or chills, dizziness and persistent vomiting. In addition to epigastric pain, persistent lower abdominal pain, diminished/loss of fetal movement and vaginal bleeding or escape of fluids, in addition oliguria or dysuria, and seizure or loss of consciousness. ${ }^{(11)}$

WHO had recommended 4 antenatal visits as the minimum accepted level. Simultaneously it emphasized the necessity of establishing clear defined objectives to be achieved during each visit. Inadequate ANC is defined as starting care after the fifth month of pregnancy or beginning earlier but receiving fewer than half of the recommended visits. ${ }^{(12)}$

Despite the efforts done to urge woman to seek ANC, slightly more than one quarter of Egyptian pregnant woman do not receive ANC (according to Egypt Demography and health survey). Several factors may shape women's utilization of ANC service: socio-economic status, availability, accessibility, previous experiences in different health settings, last but not least their satisfaction with the quality of care provided to them. ${ }^{(13)}$

Quality of care is defined as the degree to which health services for the individuals and population increase the likelihood of desired health outcomes and are consistent with current professional knowledge. (14) Many studies adopted Donabedian's conceptual framework for assessing quality of care. This framework begins with a structure that is utilized through a specific process to fulfill an outcome. Structure refers to prerequisites, such as hospital buildings, staff and equipment. While the process describes how structure is put into practice such as specific therapies. Finally outcome refers to results of processes, for instance, results of therapy. ${ }^{(14,15)}$

Antenatal care has been designated as one of the four Pillars of Safe Motherhood, along with clean and safe delivery, essential obstetric care and family planning. These four pillars are thought to contribute to reduction of maternal mortality. The quality of ANC is an effective route to emergency obstetric care and skilled delivery. Consequently it is an important determinant of pregnancy outcome. Moreover, the provision of high quality ANC is congruent with client's satisfaction toward this care. ${ }^{(16)}$

Satisfaction with quality of care is the degree to which the client's desired expectations, goals and or preferences are met by the healthcare provider and / or service. ${ }^{(17)}$ Client's satisfaction has traditionally been linked to the quality of services given and the extent to which specific needs are met. Satisfied clients are likely to come back for the services and recommended service to others. Various factors including attitude of staff, cost of care, time spent at the hospital and doctor communication have been found to influence client's satisfaction. In general satisfaction and dissatisfaction indicate client's judgment about the strengths and weaknesses, respectively, of the service. ${ }^{(17)}$

Women's satisfaction with the quality of antenatal care is an important determinant of their utilization and continuation with the service. ${ }^{(18)}$ Hence the present study aims to assess pregnant women's satisfaction with the quality of antenatal care at Maternal and child health centers in El-Beheira governorate. It is hoped that the findings of this study will help in service improvements that are responsive to women's needs \& perception \& result in improved access to and utilization of safe maternal health services.

\section{Aim of the study was:}

1. To assess pregnant women's satisfaction with the quality of antenatal care at maternal and child health centers in El-Beheira Governorate.

2. To assess the quality of antenatal care provided at maternal and child health centers in El-Beheira Governorate.

\section{Research questions:}

1. What is the level of pregnant women's satisfaction with the quality of antenatal care at maternal and child health centers in El-Beheira Governorate?

2. What is the level of quality of antenatal care provided at maternal and child health centers in El-Beheira Governorate? 


\begin{abstract}
Materials
1. Alhilal $\mathrm{MCH}$ center from Damanhour district

2. MCH Awol from Kafr El Dawar district

3. El Mahmoudiyah MCH center from El Mahmoudiyah district

4. Shubrakhit MCH center from Shubrakhit district

5. Kwm Hamada MCH center from Kwm Hamada district

6. Abu al-Matamir MCH center from Abu al-Matamir district

7. Housh Eissa MCH center from Housh Eissa district:
\end{abstract}

II. Materials and Method

Research design: A descriptive exploratory research design was utilized in this study.

Setting: The study was conducted at seven $\mathrm{MCH}$ centers affiliated to Ministry of Health in El-Beheira Governorate. These centers were chosen through a multi-stage probability sampling technique; as follows: By simple random sampling technique seven districts were picked up from the available sixteen districts in ElBeheira Governorate. Then one Maternal and Child Health $(\mathrm{MCH})$ center was selected by simple random sampling techniques- from each of the seven formerly selected districts. These seven $\mathrm{MCH}$ centers are:

\title{
Subjects:
}

A convenience sample of 350 pregnant women who were attending the antenatal clinic in the previously mentioned setting (50 from each center) were recruited. They were selected according to the following criteria: with normal pregnancy, free from medical diseases and willing to participate in the study.

The sample size was determined through the utilization of Epi info 7 program, using the following parameter:

1. Target population 1370 per 6 months.

2. Expected frequency $\mathrm{p}=50 \%$.

3. Acceptable error $=5 \%$.

4. Confidence coefficient $=95 \%$.

5. Sample size $=350$.

Tools: Three tools were used for data collection.

Tool I: Basic data structured interview schedule:

This tool was developed by the researcher. It included: Socio-demographic characteristics: age, level of education, occupation as well as number of living children.

\section{Tool II: Women's satisfaction structured interview schedule:}

It was developed by Srivastava A et al (2010) ${ }^{(19)}$ then revised by Enabor O et al (2013) ${ }^{(17)}$ to measure the pregnant women's satisfaction with the received antenatal care. It was translated into Arabic by specialist in English language translation. The version was revised and then back translated into English by another translator. The translation was refined after back translation until agreement was obtained among the two translators. It contained 53 statements. Each one was scored on a three point likert - scale ranging from 1-3. Highly satisfied take 3, moderately satisfied take 2 and dissatisfied take 1 . For each subject the total scores ranged from 53-159. Accordingly each subject satisfaction level was categorized as follow: Unsatisfied $<88$, moderate satisfaction 88 to $<123$ and highly satisfied $\geq 123$.

Tool III: Quality of antenatal care observational checklist.

It was developed by Mgawadere F (2009) ${ }^{(20)}$ to measure the quality of antenatal care. It consists of two parts. The first part: aimed to measure the quality of center's structure. It contained 30 items to assess infrastructure, universal precautions, staff, medical drugs, vaccinations, equipments \& supplies. Each item was scored by 2 if answer yes or 1 if answer no. The total score for each center ranged between 30- 60. Accordingly each of the center's structure quality was scored as follows: Low structure quality $<45$ and high structure quality $\geq 45$.

The Second part: aimed to measure the process of quality care inside the center. It contained 51 items to assess antenatal coverage, services and procedures provided (history taking, physical examination (general \& specific), measure of vital signs, laboratory investigations (blood \& urine), universal precautions), antenatal counseling, privacy \& confidentiality, respectful behavior and emotional support. Each item was scored on a three point likert- scale ranging from 1-3. Well done take 3, fairly done take 2 and not done take 1 . The total scores for each center ranged between 51- 153. Accordingly, the process of quality care was scored as follows: Low quality $<85$, Moderate quality $85-<119$ and High quality $\geq 119$. 
The third part: aimed to measure the outcome of the quality of care provided by the center. It contained 3 items to assess number of antenatal visits, time of the first antenatal visit, and recommended eleven interventions (measuring height, measuring weight, measuring blood pressure, blood investigation ( for Hb \& grouping), urine analysis, tetanus vaccination, iron or Folic Acid supplementation, prevention of sexually transmitted infections, provide counseling, had intestinal parasite drugs, discuss the plan and preparation for delivery). The total quality outcome classified as follows:

High quality outcome indicated that initiation of antenatal visit during first trimester, attendance of four visits or more as well as reception of at least nine out of the recommended eleven antenatal interventions.

Moderate quality outcome indicated that initiation of antenatal visit during second trimester, attendance of four visits or more as well as reception of at least 6-8 out of the recommended eleven antenatal interventions.

Low quality outcome indicated that initiation of antenatal visit during third trimester, attendance of less than four visits as well as reception of at least five out of the recommended eleven antenatal interventions.

\section{Method:}

1. An official letter from Faculty of Nursing - University of Damanhour was directed to the responsible authorities of the previously mentioned study centers to obtain their permission for conducting the study.

2. Tool (I) was developed by the researchers after review of recent relevant literature.

3. Tool (II) was adapted and translated into Arabic language. It was tested for reliability by test- retest technique the Cronbach's alpha test was 0.92 .

4. Tool (III) was adapted by the researchers. It was tested for reliability by inter-rater technique the Cronbach's alpha test was 0.97 .

5. Tools were tested for content validity by a jury of five experts in the field.

6. A pilot study was conducted on 35 pregnant women from the previously mentioned centers (excluded from the study subjects) to ascertain the clarity, feasibility and applicability of the tools and to identify obstacle that might interfere with the process of data collection.

7. Each subject was individually interviewed after receiving her care. The duration of each interview ranged between15-20 minutes. Two days / week were specified for data collection over a period of seven months, started from the beginning of June till the end of December 2016. An average of 5-7 interviews were performed /day.

8. Each center was observed for two hours twice weekly, until the tool III was covered.

\section{Statistical analysis}

The collected data was revised, categorized, coded, computerized, tabulated and analyzed using statistical package for social sciences (SPSS) version 16. Descriptive and analytical statistics were used such as frequency, percentages, Pearson correlation coefficient. Significance was adopted at $\mathrm{P}<0.05$ for interpretation of results of tests of significance.

\section{Ethical considerations}

For each subject an informed oral consent was obtained after explaining the purpose of the study. In addition her anonymity, privacy, freedom to withdraw from the study at any time and confidentiality of her data were all emphasized prior starting the interview.

\section{Results}

Table (1) shows the socio-demographic characteristics of the study subjects. The age of one-half (50\%) of the study subjects were between 20 to less than 30 years and about one-third (34\%) of them were less than 20 years. More than one-third (36\%) of them had secondary education, and $30 \%$ were illiterate or just read and write. The majority (84.9\%) of study subjects were housewives. More than two-fifths (44.9\%) of them had three children or less.

Table (2) describes distribution of the study subjects according to their satisfaction with the specific items of antenatal care. More than three-fifths $(63.4 \%)$ of the study subjects were unsatisfied with setting's accessibility. One-half $(50.0 \%)$ of them were unsatisfied with the setting's infrastructure. And the majority $(84 \%)$ of them were unsatisfied with the availability of drugs, equipment's \& supplies. As well as more than three-fifths $(62.9 \%)$ of study subjects were unsatisfied with the overall setting's structure. The majority of them $80 \%$ \& $83.4 \%$ were unsatisfied with the services timing and counseling respectively. And more than three-fifths $(64 \%)$ of them were unsatisfied with the physical care. While three-quarters of study subjects $(75.1 \%)$ were highly satisfied with registration process. More than one-half $(52 \%)$ of them were highly satisfied with the received psychological care. In addition, more than one-half $(53.4 \%)$ of the study subjects were unsatisfied with 
Pregnant women's satisfaction with the quality of antenatal care at maternal and child health ..

the overall process of care. When it comes to cost, $66 \%$ were highly satisfied. About three-fifths (58.9\%) of them were unsatisfied with the overall antenatal care services.

Table (3) shows distribution of $\mathrm{MCH}$ centers according to their quality of care. The majority (85.7\%) of MCH centers had low structure quality. And nearly three-quarters (71.4\%) of them had low quality process of care. In relation to overall quality of care, more than one-half (57.1) of MCH centers had low quality of care. And $28.6 \%$ of them had moderate quality of care, while only $14.3 \%$ of them had high quality.

Table (4) distribution of quality of antenatal care outcome provided to study subjects in the seven $\mathrm{MCH}$ centers. More than three-fifths (62\%) of the study subjects received less than four antenatal visits. And more than one-half $(54 \%)$ of them started their antenatal visits during their second trimester, while only $18 \%$ of them had started it in their first trimester. As regard the recommended interventions, almost all (99.1\% \& 95.1) of the study subjects received measuring for blood pressure and weight respectively, and $95.7 \%$ of them done blood investigation. The majority $(81.7 \%)$ of the study subjects received tetanus vaccination. $71.4 \%$ of them received iron or folic acid supplementation.

Figure (1) shows distribution of overall quality of care outcome provided in the seven MCH centers. More than two-fifths (42.9\%) of the overall quality of care outcome in the seven centers was low. And more than one-third of it (34.2\%) was moderate. Only $22.9 \%$ of it was high.

Table (5) shows the relationship between level of quality of care among the seven centers and the study subjects' overall satisfaction. It demonstrates a positive statistically significant correlation between study subject's overall satisfaction and the centers' quality of care structure $(\mathrm{P}=0.005)$, process $(\mathrm{P}=0.001)$, outcome $(\mathrm{P}=0.000)$ and the overall quality of care $(\mathrm{P}=0.000)$. It indicates that a decrease in the quality of care level is followed by a decrease in the clients' satisfaction level.

Table (1): Number \& percent distribution of the study subjects according to their socio-demographic characteristics

\begin{tabular}{|l|c|c|}
\hline Socio-demographic characteristics & No $=350$ & \% \\
\hline Age: (years) & 119 & 34.0 \\
$<20$ & 175 & 50.0 \\
20- & 56 & 16.0 \\
30 or more & & \\
\hline Level of education: & 105 & 30.0 \\
-Illiterate or just read and write & 91 & 26.0 \\
-Basic education & 126 & 36.0 \\
-Secondary education & 28 & 08.0 \\
-University education & & \\
\hline Occupation:- & 297 & 84.9 \\
-Housewife & 53 & 15.1 \\
-Working & & \\
\hline Number of living children: & 88 & 25.1 \\
-None & 157 & 44.9 \\
- $\leq 3$ & 105 & 30.0 \\
- 4 or more & & \\
\hline
\end{tabular}

Table (2): Number $\&$ percent distribution of the study subjects according to their satisfaction with the specific items of antenatal care

\begin{tabular}{|c|c|c|c|c|c|c|}
\hline \multirow[t]{2}{*}{ Satisfaction with ANC items } & \multicolumn{2}{|c|}{ Highly satisfied } & \multicolumn{2}{|c|}{ Moderately satisfied } & \multicolumn{2}{|c|}{ Unsatisfied } \\
\hline & No & $\%$ & No & $\%$ & No & $\%$ \\
\hline 1- Accessibility & 69 & 19.7 & 59 & 16.9 & 222 & 63.4 \\
\hline $\begin{array}{l}\text { 2- Structure: } \\
\text { - Infrastructure } \\
\text {-Availability of drugs, equipment \&supply }\end{array}$ & $\begin{array}{c}70 \\
7\end{array}$ & $\begin{array}{l}20.0 \\
02.0\end{array}$ & $\begin{array}{c}105 \\
49\end{array}$ & $\begin{array}{l}30.0 \\
14.0\end{array}$ & $\begin{array}{l}175 \\
294\end{array}$ & $\begin{array}{l}50.0 \\
84.0\end{array}$ \\
\hline overall structure & 42 & 12.0 & 88 & 25.1 & 220 & 62.9 \\
\hline $\begin{array}{l}\text { 3- Process of care items: } \\
\text {-Services timing } \\
\text {-Registration } \\
\text {-Physical care } \\
\text {-Privacy\& confidentiality } \\
\text {-counseling } \\
\text {-psychological care }\end{array}$ & $\begin{array}{c}11 \\
263 \\
73 \\
101 \\
17 \\
182\end{array}$ & $\begin{array}{l}03.1 \\
75.1 \\
20.9 \\
28.9 \\
04.9 \\
52.0\end{array}$ & $\begin{array}{l}59 \\
70 \\
53 \\
81 \\
41 \\
63\end{array}$ & $\begin{array}{l}16.9 \\
20.0 \\
15.1 \\
23.1 \\
11.7 \\
18.0\end{array}$ & $\begin{array}{c}280 \\
17 \\
224 \\
168 \\
292 \\
105\end{array}$ & $\begin{array}{l}80.0 \\
04.9 \\
64.0 \\
48.0 \\
83.4 \\
30.0\end{array}$ \\
\hline -overall process of care & 95 & 27.2 & 68 & 19.4 & 187 & 53.4 \\
\hline 4- Cost & 231 & 66.0 & 98 & 28.0 & 21 & 06.0 \\
\hline Satisfaction with overall ANC & 50 & 14.2 & 94 & 26.9 & 206 & 58.9 \\
\hline
\end{tabular}


Table (3) Number \& Percent distribution of MCH centers according to their quality of care

\begin{tabular}{|l|c|c|}
\hline \multicolumn{1}{|c|}{ Items of quality of care } & No= & \% \\
\hline Structure: & & 85.7 \\
- Low structure quality & 6 & 14.3 \\
- High structure quality & 1 & 71.4 \\
\hline Process of care: & 5 & 14.3 \\
- Low quality & 1 & 14.3 \\
- Moderate quality & 1 & 57.1 \\
- High quality & & 28.6 \\
\hline Overall quality of care: & 4 & 14.3 \\
- Low quality & 2 & \\
- Moderate quality & 1 & \\
- High quality & & \\
\hline
\end{tabular}

Table (4) Number \& Percent distribution of quality of antenatal care outcome provided to study subjects in the seven MCH centers

\begin{tabular}{|l|c|c|}
\hline \multicolumn{1}{|c|}{ quality of ANC outcome } & No= 350 & \% \\
\hline Number of antenatal visits: & 217 & 62.0 \\
- Less than four visits & 133 & 38.0 \\
- Four or more & & 18.0 \\
\hline Timing of the first antenatal visit: & 63 & 54.0 \\
- First trimester & 189 & 28.0 \\
- Second trimester & 98 & 33.7 \\
- Third trimester & & 95.1 \\
\hline Recommended interventions: & 118 & 99.1 \\
- Measuring height & 333 & 95.7 \\
- Measuring weight & 347 & 62.9 \\
- Measuring blood pressure & 335 & 81.7 \\
- Blood investigation (for Hb \& grouping) & 220 & 71.4 \\
- Urine analysis & 286 & 33.1 \\
- Tetanus vaccination & 250 & 04.9 \\
- Iron or Folic Acid supplementation & 116 & 10.0 \\
- Prevention of sexually transmitted infections & 17 & 16.0 \\
- Provide counseling & 35 & 56 \\
- Had intestinal parasite drugs & & 56 \\
- Discuss the plan and preparation for delivery & & \\
\hline
\end{tabular}

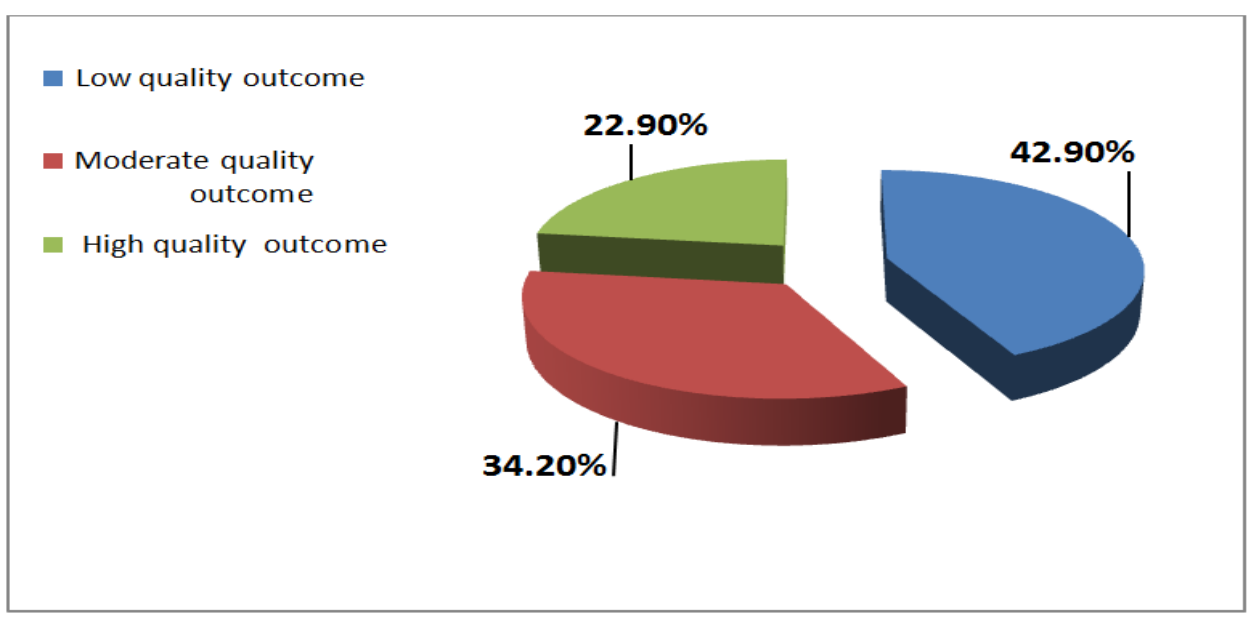

Figure (1) Percent distribution of overall quality of care outcome provided in the seven MCH centers

Table (5): Correlation between level of quality of care among the seven MCH centers and the study subjects' overall satisfaction

\begin{tabular}{|l|c|}
\hline \multirow{2}{*}{ Quality of care } & Overall satisfaction \\
\cline { 2 - 2 } & $\mathrm{r}(\mathrm{P})$ \\
\hline Structure & $0.198(0.005)^{*}$ \\
\hline Process of care & $0.340(0.001)^{*}$ \\
\hline Outcome of care & $0.524(0.000)^{*}$ \\
\hline Overall Quality of care & $0.317(0.000)^{*}$ \\
\hline
\end{tabular}


Pregnant women's satisfaction with the quality of antenatal care at maternal and child health ..

r: Pearson correlation coefficient $* \mathrm{P} \square 0.05$ (significant)

\section{Discussion}

Among the various pillars of Safe Motherhood, antenatal care remains one of the interventions that have the potential to significantly reduce maternal morbidity and mortality when properly conducted. Improve maternal and newborn health by improving the quality of care provided at primary healthcare (PHC) facilities. $(21,22)$ Quality of health care can be accessed from two perspectives, quality of health care and client's satisfaction with the manner in which the service is delivered. ${ }^{(23)}$ The aim of this study was to assess pregnant women satisfaction with quality of antenatal care at Maternal and Child Health Centers in El-Beheira governorate.

According to the results of the current study it can be noticed that more than one half of the study subjects $(58.9 \%)$ were unsatisfied with the overall antenatal care services, more than one quarter of them $(26.9 \%)$ were moderately satisfied and only $14.2 \%$ were highly satisfied. The current finding is relatively similar to the study of Arafat A (2015) ${ }^{(24)}$ in Alexandria, Egypt, titled "pregnant women's expectations versus care delivered during initial antenatal visit". She found that only $30.1 \%$ of her subjects were highly satisfied with the received care. On the other hand, the current study also doesn't correspond with the study of Fawole A et al (2008) ${ }^{(18)}$ in their study about clients' perceptions of the quality of antenatal care in Ibadan, Nigeria. They found that $81.1 \%$ of their study subjects were satisfied with ANC services. The current finding also doesn't match with the study of Mansour S et al (2012) ${ }^{(25)}$ in Al-madinah Al-menawarh, Saudi Arabia about women's satisfaction with the quality of antenatal care at the primary health care centers. The study indicated that nearly two-thirds $(62 \%)$ of their subjects were satisfied with overall aspects of antenatal care services.

In addition, it is not in accordance with the finding of the study carried out in Nigeria by Enabor $\mathrm{O}$ et al (2013). ${ }^{(17)}$ The aim of this study was to investigate perception and satisfaction with quality of antenatal care services among pregnant women at the university college hospital. It was reported that $81.1 \%$ of their study's subjects were satisfied with the care they received at antenatal clinic. Moreover, the present finding is not consistent with finding of Emelumadu $\mathrm{O}$ et al (2014). ${ }^{(26)}$ They had conducted a study titled perception of quality of maternal healthcare services among women utilizing antenatal services in selected primary health facilities. This study concluded that the majority of women were satisfied with the care they received at health facilities. (26) Furthermore, the current finding disagrees with the study of Abebe S et al (2017) ${ }^{(27)}$ in Ethiopia, about "Quality of Antenatal Care Service in Public Health Facilities". This reported that $52.6 \%$ of respondents were satisfied with the service provided.

Specifically speaking almost, three-fifths $(63.4 \%)$ of the present study subjects were unsatisfied with the centers' accessibility. This result is kind of unexpected because the Egyptian Demographic and Health survey (EDHS) (2014) ${ }^{(13)}$ had reported a rating of $66 \%$ for access of antenatal care programs in Egypt. The result of the current study is nearly congruent with the findings of Montasser N et al (2012). ${ }^{\text {(28) }}$ They had conducted a study about Egyptian women's satisfaction and perception of antenatal care in Shawa village, Dakahlia governorate, Egypt. Their results revealed that nearly three-quarters (72.2\%) of their study participants were not satisfied with the accessibility of ANC service. Such an agreement between the results of the present study \& the aforementioned results could be explained by both studies were conducted in villages either in ElBeheira and Dakahlia governorates where the centers are usually present outside the villages. On the other hand, this same present finding is not consistent with the results of Sholeye O et al (2013). ${ }^{(29)}$ They had conducted a study titled " three decades after Alma-Ata: are women satisfied with antenatal care services at primary health centers" in Nigeria. Their results revealed that $88 \%$ of their subjects were highly satisfied with their services' accessibility.

Pregnant women's high satisfaction with centers' infrastructure was evident among only about one-fifth (20\%) of the present study subjects. This result is probably attributed to the actual shortage in health care providers, inadequate waiting space. In addition to, lack of sanitation, lightening, ventilation (in some centers). The present finding is agree with the study of Edie G et al (2015) ${ }^{(30)}$ about perceptions of antenatal care services by pregnant women attending governmental health centers in the Buea Health District, Cameroon, where they found that only $20 \%$ of their studies subjects were satisfied with the centers' infrastructure. ${ }^{(30)}$ On the contrary, the current study doesn't correspond with the findings of Soliman F (2015). ${ }^{(31)}$ She had conducted a study about satisfaction of rural pregnant women as quality indicator of provided antenatal care at Tanta city in Egypt. She reported that $68.6 \%$ of her study subjects were satisfied with the infrastructure of the study settings. She attributed their satisfaction to the setting's cleanliness, good ventilation, adequate light, and availability of seats in waiting areas. This discrepancy between the former study findings and the results of current study could be attributed to the fact that it was conducted in an urban area and the current study was conducted in a rural one, where the former it is expected to be 
better equipped. Cognitive and emotional support plays a crucial role in influencing women's satisfaction with care during pregnancy and childbirth. ${ }^{(32)}$

The present study revealed that slightly more than one- half $(52.0 \%)$ of the study subjects were highly satisfied with the received psychological care specifically greetings, introducing one self, referring to women's by their names, giving them time to express their feelings without interruption as well as answering their questions. This result is consistent with the finding of the previously mentioned Egyptian study by Montasser $\mathbf{N}$ et al (2012). ${ }^{(28)}$ They had reported that nearly one - half $(48 \%)$ of their subjects were satisfied with their received psychological care. This agreement between Montasser $\mathbf{N}$ et al (2012) ${ }^{(28)}$ findings and the results of current study is probably attributed to the fact that health care providers at maternal and child health centers in Egypt suffer from shortage of staff and high workload. Such conditions probably limit the care provider's chance to provide enough time and psychological care to each client.

The current study showed that more than three-fifths $(64.0 \%)$ of its participants were dissatisfied with the received physical care. The current finding is relatively in accordance with the study of Hasnain $S$ et al (2007) ${ }^{(33)}$ about " causes of low tetanus toxoid vaccination coverage among pregnant women" in Pakistan. They found that nearly three-fifths $(59.1 \%)$ of their study participants were dissatisfied with the received physical care. This result was attributed to shortage of health care providers, in the studied settings. ${ }^{(33)}$ On the other hand, This finding is different than the findings of Hildingsson I et al $(2005)^{(34)}$ and Hansen P et al (2008). ${ }^{(35)}$ They all had revealed that the majority of their subjects were satisfied with their received physical care.

The current study revealed that $75.1 \%$ of its subjects were highly satisfied with the registration process. This result agrees with Elgamel H (2014). She carried out a study about "dimensions of quality of antenatal care service at urban centers in suez canal, Egypt". She found that about $76 \%$ of her study subjects were satisfied with the registration process. ${ }^{(36)}$

Long waiting to see a physician can produce dissatisfaction and increase client's anxiety. It is frequently cited as a reason why clients leave the maternal and child health centers before receiving care. ${ }^{(37)}$ The present study revealed that the majority $(80 \%)$ of its participants were unsatisfied with the waiting time. This result is in line with the findings of two previously mentioned Saudi Arabian and Nigerian studies: Mansour S et al (2012) ${ }^{(25)}$ and Sholeye O et al (2013) ${ }^{(29)}$ respectively. Both of them had reported that a high percent of their study subjects were not satisfied with the waiting time. Such agreement between the current study finding and that of the two previously mentioned studies could be explained by the centers overcrowding and high workload due to the disproportion between the numbers of clients and health care providers. However, the present study's same result is not congruent with the findings of Balogun $\mathbf{O}(2007) .{ }^{(38)}$ His results reported a high satisfaction level about their subjects in relation to waiting time. This could be attributed to the fact that the number of clients was appropriate to the number of health care providers in the Nigerian private health settings.

One of the main antenatal care goals is the provision of adequate information that is essential for maintaining and improving pregnancy outcome. ${ }^{(39)}$ The current study indicated that the majority $(83.4 \%)$ of women were unsatisfied with the received information through counseling. This result was in congruence with the findings of many researchers, who indicated that only about one-third of their participants were satisfied with the received counseling during their antenatal care. ${ }^{(28,40,41)}$ Such an agreement between these results- in this respect- among the four studies may reflect discrepancy between clients' expectations and the actual provided counseling. In contrast, Al-Ateeq M et al $(2015){ }^{(42)}$ found that more than one- half $(53.2 \%)$ of their subjects were satisfied with the received antenatal counseling. This contradiction could be attributed to the fact that most of the health care providers in Saudi Arabia are not national. They are very keen to stay on their jobs because of their high salaries. Consequently, they provide adequate multiple health education sessions as their work load permits that. While the other studies subjects - including the present one - may have received superficial antenatal health education as their health care providers suffer from shortage of staff and high workload.

In the light of the present study results, subjects' high satisfaction with the services cost was evident among $66 \%$ of them. This result is kind of expected because they only pay a minimal fee for registration in the first visit, in addition to paying only one third of the medications cost. This result is nearly congruent with the findings of other two previously mentioned Nigerian studies. Sholeye O et al (2013) ${ }^{(29)}$ and Enabor O et al $(2013)^{(17)}$ respectively. Both of them had revealed that a high percent of their subjects were satisfied with their services costs.

The results of the present study indicated that only $14.3 \%$ of studied centers had high quality. While $28.6 \%$ of centers had moderate quality. Low quality was observed in $57.1 \%$ the centers. This result could be attributed to the fact that most of the centers have inadequate waiting space beside lack of proper sanitation. Specifically, waters supply, enough lightening, ventilation, cleanliness and directional signals. In addition, all centers are not complying with the ministry of health infection control guidelines. Moreover, most of the centers have dearth of health care providers, where each antenatal clinic within the centers have only one nurse and one physician. Furthermore, these care providers have to work in more than one clinic to cover their colleagues' absence. Beside shortage of some necessary equipment and drugs. 
This finding is supported by Mgawadere F (2009). ${ }^{(20)}$ She had reported that less than one-third (29\%) of her studied centers had high level of quality of care. She had attributed her results to infrastructure problems such as, shortage of health care providers, equipment and supplies. In addition, this finding is in line with Nnebue C et al (2015) ${ }^{(43)}$ who asserted that a minority of their studied centers had good quality of care. They had attributed their results to their poor referral systems and the disproportion between centers' capacity and the number of their clients. This finding is almost similar to the study of Abebe $\mathrm{S}$ et al (2017), ${ }^{(27)}$ which concluded that the overall quality of ANC service was poor which may be explained by shortage of reagents and drugs, absences of guidelines, absence of trainings, absence of incentives, absence of regular supervision, inadequate health information for mothers and absence of privacy.

Furthermore, this finding is in congruence with Majrooh M et al (2014) ${ }^{(44)}$ who reported that only onethird of their studied centers had good quality of care. They attributed their results to shortage of midwifes, necessary equipment, drugs and lack of centers cleanliness and sanitation. On the contrary, Nikiema L et al $(2010)^{(45)}$ found that one-half $(50 \%)$ of their studied centers have high quality of care. This disagreement between the findings of this study and the current study -in this respect- may be attributed to the fact that the aforementioned study sample size (17 centers) almost doubled those of the current study's sample ( 7 centers). Where the large sample size in the former one may have provided a wider range of variations in the quality of antenatal care at the centers.

The outcome of the quality of care in this study was measured by: number of antenatal visits, timing of the first antenatal visits and the provision of the main recommended interventions. The present study revealed that the overall quality of care outcome in the seven centers was low $(42.9 \%)$. In relation to the number of antenatal visits, More than three-fifths $(62 \%)$ of the clients had attended less than four antenatal visits. These results are not consistent with WHO (2005). ${ }^{(46)}$ Recommendation of at least four visits during normal pregnancy. Accordingly, this result indicates a poor quality outcome. As regard the time of the initial visit, more than one-half $(54 \%)$ of the subjects had started their antenatal visits in their second trimesters. Again this result is not in line with WHO (2006) ${ }^{(47)}$. Recommendation that first antenatal visit should be done during the first trimester of pregnancy, preferably before sixteen week. Consequently, this result is indicating a low quality outcome. In addition, more than two-fifths (43.8\%) of them had received less than eight antenatal services. This result is consistent with findings of a previously mentioned Malawian study by Mgawadere F (2009). ${ }^{(20)}$ Her results concluded that two-thirds of the overall quality of care outcome in her studied centers was moderate. Where as much as $40.5 \%$ of her subjects had started their antenatal visits during their second trimester. In addition less than one-half of them did receive less than four antenatal visits. This agreement between the pervious study findings and the current one may be interpreted by fact that both studies were conducted in rural areas. Where rural pregnant women in El-Beheira, Egypt and Lungwena, Malawi are expected to be less aware about the importance of early initiation of ANC. Consequently, the number of their visits would be less than four visits.

The present study clarified the presence of a positive statistically significant correlation between its subjects overall satisfaction level and overall quality of care in the centers. This result is in line with the Emergency Medicine Practice Committee ACEP (2011). ${ }^{(48)}$ Report it indicated the presence of a positive significant relationship between patients' satisfaction and quality of care. In addition to the findings of other two researches. Firstly, Doaee S et al (2013). ${ }^{(49)}$ They had conducted a study titled "women's attitude to group prenatal care and their satisfaction" in Iran. Secondly, Dhahi Z et al (2014). ${ }^{(50)}$ They had conducted a study titled "study on pregnant women's satisfaction with primary health care services in Basra "Iraque". Both researches revealed the presence of a significant relation between pregnant women's overall satisfaction level and quality of care at primary health centers. Yet, they didn't decide the type of the relationship whether it was positive or negative. They attributed their subjects' high satisfaction level to several factors: accessibility of the studied settings, health care providers, positive attitudes, availability of female physicians as well as the affordability of the services' costs.

As much as $14.2 \%$ of the present study subjects were highly satisfied with the overall aspects of the introduced ANC at the selected centers, in spite of the fact that as much as $57.1 \%$ of these centers quality of services was low. this observation could be explained by the notion that pregnant women's expectations in the present study was low as a substantial proportion (84.9\%) of them were housewives with low socioeconomic status and the cost of services are reasonable for them in comparison with the private clinics. In addition, the fact that one-half of them were either illiterate $(30 \%)$ or have primary education $(26 \%)$. Accordingly they become satisfied with the humble level of care.

\section{Conclusion}

Based on the findings of the present study, it could be concluded that quality of antenatal care provided at studied MCH centers in El-Beheira governorate was poor, this due to lack of proper infrastructure for providing antenatal care, shortage of staff, lack of necessary medications, vaccination, equipments and supplies. The 
pregnant women were unsatisfied with the antenatal care provided in these centers. It indicates that a decrease in the quality of care level is followed by a decrease in the clients' satisfaction level.

\section{Recommendations}

Based on the findings of the present study, the following recommendations are suggested:

1. The Ministry of Health through the district health implementation plan should consistently provide adequate number of staff, supplies, equipments and drugs for providing antenatal care

2. Continuous training of the health care providers at maternal and child health center is recommended as it may improve their performance and consequently raise the quality level.

3. Continuous monitoring of clients' satisfaction with all aspects of care could aid in improvement of the quality of services.

4. Different health education methods should be available to increase awareness of the pregnant women about the importance and components of antenatal care.

5. Further researches:

- Further studies to investigate the possible applicable strategies for amelioration of antenatal quality of care.

- Further study to identify the pregnant women expectations versus received antenatal care.

\section{References}

[1]. Koppad S, Walvekar R, Mallapur D. Utilization of Antenatal Care by Pregnant Women Reading in Kakati Sub Center. Indian Journal of Public Health Research \& Development 2014; 5(3):160

[2]. Radhika K. A Study To Assess The Knowledge of Selected Warning Signs In Pregnancy Among Primi - Gravida Women In Kempa Cheluvamba General Hospital, Malleswaram, Bangalore. Published Masters of Science (Nursing) in Obstetrics and Gynecology. Rajiv Gandhi University of Health Sciences, Karnataka, Bangalore, India. November 2005.

[3]. WHO, UNICEF, UNFPA, World Bank Group and the United Nations Population Division. Trends in maternal mortality: 1990 to 2015. Geneva: WHO. Available at URL: http://www.who.int/mediacentre/factsheets/fs348/en/. Retrieve.on:1 February 2016.

[4]. Campbell O, Gipson R, Issa AH, Matta N, El Deeb B, El Mohandes A, Alwen A, Mansour E. National maternal mortality ratio in Egypt halved between 1992-93 and 2000. Bull World Health Organ. 2005; 83(6):462 -71.

[5]. Marshall J, Raynor M. Myles textbook for midwives. 16th ed. Edinburgh: Churchill Livingstone, $2014 ; 251-63$.

[6]. Adele Pillitteri. Maternal and Child Health Nursing. $7^{\text {th }}$ ed. Lippincott Williams \& Wilkins, 2013; $347-348$.

[7]. Phelps K, Hassed C. Pregnancy \& Antenatal Care: General Practice: The Integrative Approach Series. Australia: Churchill Livingstone, 2011; 167-169.

[8]. Jacob A. A Comprehensive Textbook of Midwifery and Gynecological Nursing, $3^{\text {rd }}$ ed. London: Jaypee Brothers Medical Publishers (P) Ltd, 2012; 106-107.

[9]. Hatfield N. Introductory Maternity and Pediatric Nursing. $3^{\text {rd }}$ ed. China: Wolters Kluwer Health/ Lippincott Williams \& Wilkins, 2013; 137-163.

[10]. Simpson K, Creehan P. AWHONN's Prenatal Nursing. $4^{\text {th }}$ ed. China: Wolters Kluwer Health/ Lippincott Williams \& Wilkins, 2014; 95-96.

[11]. Hockenberry P. Maternal Child Nursing Care. $5^{\text {th }}$ ed. Canada: Mosby Elsevier, 2012; 483-9.

[12]. World Health Organization. A listing of available information: Coverage of maternal care. 2010. Available at URL: http://www.who.int/whosis/whostat/EN_WHS10_Full.pdf. Retrieved on: 20 October 2016.

[13]. El Zanaty F, Way A. Egypt Demographic and Health Survey 2014. Ministry of Health. Cairo, Egypt: 2014; $109-127$.

[14]. Hickey J, Brosnan C. Evaluation of Health Care Quality in Advanced Practice Nursing. United States: Springer Publishing Company, LLC, 2012; 7-11.

[15]. Jan F, Tabish S. Step by Step Quality Hospital Care. New Delhi: Jaypee Brothers Medical Publishers (P) Ltd, $2013 ; 40-41$.

[16]. Mohamed A, Refat T. Egyptian women's satisfaction and perception of antenatal Care. International Journal of tropical diseases and Health 2012; 2(2): 145-56.

[17]. Enabor O, Nwaeze I, Ouwasola T. Perception \& Satisfaction of the quality of antenatal care among pregnant women in Nigeria. Annual of Ibadan Postgraduate Medicine Journal 2013; 1(11): 140-52.

[18]. Fawole A, Okunlola M, Adekunle A. Clients' Perceptions of the Quality of Antenatal Care. J Natl Med Assoc 2008; 100(9):1052-8.

[19]. Srivastava A, avan B, Rajbangshi p. Determinants of Women's Satisfaction with Maternal Health Care: a Review of Literature from Developing Countries . BMC Pregnancy Childbirth 2010; 18 (4): 51-60.

[20]. Mgawadere F. Assessing the Quality of Antenatal Care at Lungwena Health Centre in Rural Malawi. Published Master Thesis. College of Medicine, University of Malawii; 2009.

[21]. Cohen J. Patient satisfaction with prenatal care provider and the risk of cesarean delivery. Am J Obstet Gynecol 2005; 192: 202934

[22]. Turan J, Bulut A, Nalbant H, Akalin A. The quality of Hospital based Antenatal care in Istanbul. Stud Fam Plann 2006; 37(1): 4960 .

[23]. Chow A, Mayer E, Darzi A, Athanasiou T. Patient-reported outcome measures: the importance of patient satisfaction in surgery. Surgery 2009; 146: 435-43.

[24]. Arfat A. Pregnant Women's Expectations Versus Care Delivered during Initial Antenatal Visit. Unpublished Master Thesis. Faculty of Nursing, Alexandria University; 2015.

[25]. Mansour S, Elsaba H. Women's Satisfaction with the Quality of Antenatal Care at the Primary Health Care Centers in Al-Madinah Al-Menawarh, KSA. Life Sci J 2012; 9 (4): 4291-9. 
[26]. Emelumadu O, Onyeonoro U, Ukegbu A, Ezeama N, Ifeadike C, Okezie O. Perception of Quality of Maternal Healthcare Services among Women Utilizing Antenatal Services in Selected Primary Health Facilities in Anambra State, Southeast Nigeria. Niger Med J 2014; 55(2):148-55.

[27]. Abebe S, Alemayehu A, GebremariamA ,Dirar A. Quality of Antenatal Care Service in Public Health Facilities of Chencha District, GamoGofa Zone, Southern Ethiopia. MOJ Women's Health 2017; 4(3): 00086. DOI: 10.15406/mojwh.2017.04.00086

[28]. Montasser N, Helal R, Megahed W, Amin S, Saad A, Ibrahim T. Egyptian Women's Satisfaction and Perception of Antenatal Care. Int J Tropic Dis Health 2012; 2(2): 145-56.

[29]. Sholeye O, Abosede O, Jeminusi O. Three Decades after Alma-Ata: are Women Satisfied with Antenatal Care Services at Primary Health Centers in Mushin, Lagos. J Med Sci Res 2013; 2 (3): 24-9.

[30]. Edie G , Obinchemti D, Tamufor E, Njie M, Njamen T . Perceptions of Antenatal Care Services by Pregnant Women Attending Governmental Health Centers in Cameroon.pan J of Africa medical. 2015; 21: 45-50.

[31]. Soliman F. Satisfaction of Rural Pregnant Women as Quality Indicator of Provided Antenatal Care at Tanta City in Egypt. Int J Sci Res Pub 2015; 5(3): 1-9.

[32]. Hodnett E, Gates S, Hofmeyr G, Sakala C. Continuous support for women during childbirth. Cochrane Database Syst Rev. 2013; Issue 7. Art. No.:CD003766. DOI: 10.1002/14651858.CD003766.pub5.

[33]. Hasnain S, Sheikh N. Causes of Low Tetanus Toxoid Vaccination Coverage in Pregnant Women in Lahore District, Pakistan. East Mediterr Health J 2007; 13(5):1142-52.

[34]. Hildingsson I, Rådestad I. Swedish Women's Satisfaction With Medical and Emotional Aspects of Antenatal Care. J Adv Nursing 2005; 52(3): 239-49.

[35]. Hansen P, Peters D, Viswanathan K, Rao K, Mashkoor A, Burnham G. Client Perceptions of the Quality of Primary Care Services in Afghanistan. Int J Qual Health Care 2008; 20(6):384-91.

[36]. Elgamel H. Dimensions of Quality of Antenatal Care Service at Suez Canal, Egypt. Family Medicine J and Primary Care 2014; 3(5): 238-242.

[37]. Prakash B. Patient Satisfaction. Cutaneous Aesthetic Surg J 2010; 3(3): 151-155.

[38]. Balogun O. Patient Perception of Quality of Antenatal Care Service in four Selected Private Health Facilities in Ilorin, Kwara State of Nigeria. Nigerian Med Prac 2007; 51(4): 80-4.

[39]. Ekabua K, Njoku C. Proposed Framework for Making Focused Antenatal Care Services Accessible: A Review of the Nigerian Setting. International J Scholarly Research Notices 2011;17(11): 13-5.

[40]. Kajuri M, Karimi S, Shekarabi R ,Hosseini F . Investigating Women's Satisfaction with Prenatal Care Received at the Primary Health Care Centers in Iran. Internet J of obstetrics and gynecologic 2006; 7(1): 50-3.

[41]. Nisar N, Amjad R. Pattern of Antenatal Care Provided at a Public Sector Hospital Hyderabad Sindh. J Ayub Med Coll Abbottabad 2007;19(4): 11-3.

[42]. Al-Ateeq M, Al-Rusaiess A. Health Education during Antenatal Care: the Need for More. Int J Women's Health.2015; 7: $239-42$.

[43]. Nnebue C, Ebenebe U, Adinma E, Iyoke C, Obionu C, Ilika A. Clients' knowledge, Perception and Satisfaction with Quality of Maternal Health Care Services at the Primary Health Care Level in Nnewi, Nigeria. Niger J Clin Pract 2014; 17(5):148-55.

[44]. Majrooh M, Hasnain S, Akram J, Siddiqui A, Memon Z. Coverage and Quality of Antenatal Care Provided at Primary Health Care Facilities in the 'Punjab' province of 'Pakistan'. plos one J 2014; 9(11):113-39.

[45]. Nikiema L, Kameli Y, Capon G, Sondo B, Prével Y. Quality of Antenatal Care and Obstetrical Coverage in rural Burkina Faso. J Health Popul Nutr 2010; 28(1): 67-75.

[46]. WHO, Europe. What is the effectiveness of antenatal care? (Supplement) WHO Regional Office for Europe's Health Evidence Network (HEN) December 2005

[47]. WHO. Provision of Effective Antenatal Care. Geneva. World Health Organization 2006.vailable.at.URLhttp://apps.WHO.int/iris/bitstream/10665/63878/1/WHO_RHT_MSM_06.pdf. Retrieved.on:20. Jun 2016.

[48]. Emergency Medicine Practice Committee ACEP. Patient Satisfaction. American College of Emergency Physicians policy 2011. Available.at.URL. http://www.acep.org/patient satisfaction/. Retrieved.on:20.jaun 2016.

[49]. Doaee S, Nejati M, Heidari R, Haghollahi F. Women's Attitude to Group Prenatal Care and their Satisfaction. J Pak Med Assoc 2013; 63: 50-4.

[50]. Dhahi Z, Issa S, Hameed L. Pregnant Women's Satisfaction with Primary Health Care Services in Basra. International J of Research in Humanities, Arts and Literature. 2015; 3(2): 7-20. 